\title{
Enabling laboratory medicine in primary care through EMR systems use: A survey of Canadian physicians
}

\author{
Louis Raymond \\ Université du Québec à Trois-Rivières \\ louis.raymond@uqtr.ca
}

\author{
Guy Paré \\ HEC Montréal \\ guy.pare@hec.ca
}

\author{
Éric Maillet \\ Université de Sherbrooke \\ eric.maillet@usherbrooke.ca
}

\begin{abstract}
Important problems remain with regard to the efficiency and effectiveness of laboratory testing in primary care. In view of this, a significant function of electronic medical record (EMR) systems is to enable the practice of laboratory medicine by primary care physicians $(P C P s)$. In addressing this issue, the present study aims to deepen our understanding of the nature and effectiveness of PCPs' use of EMR systems for patient management and care within the laboratory testing process. To achieve our main objective, a survey of 684 Canadian physicians was realized. Results confirm that the artefactual and clinical contexts of EMR use influence the extensiveness of this use for communicational and clinical purposes. In turn, it is confirmed that the more extensive the use of EMR for laboratory medicine, the greater its impacts on the $P C P$ s' efficiency and on the quality of care provided by these physicians. The implications of these results are discussed.
\end{abstract}

\section{Background}

In the face of ever-increasing healthcare costs due to an aging population and a concomitant rise in chronic illnesses, governments in most developed countries, including those with national healthcare systems such as the United Kingdom and Canada, have felt the need to improve the efficiency and effectiveness with which primary medical care is given to their citizens [1]. This has led to a greater emphasis on the prevention and monitoring roles played by primary care physicians (PCPs) through their practice of laboratory medicine [2]. These physicians must rely on laboratory results to screen for diseases, diagnose medical problems, and monitor the health condition of patients, especially their chronically-ill patients [3]. That being said, laboratory testing tends to be a fragmented process in which many different tasks are performed at different locations by different physicians, nurses and allied healthcare professionals [4]. Moreover, the circumstances that surround PCPs' ordering of tests may vary greatly and involve several steps between their initial evaluation and the moment at which they take clinical action [5]. The PCPs' efficiency and, more importantly, the quality of care may be negatively affected by laboratory information that is incomplete, imprecise, scattered, conflicting, or erroneous [6]. The medical errors that ensue, and their associated costs, are therefore of serious concern to all healthcare stakeholders because laboratory tests are prescribed in approximately 30 to $40 \%$ of PCPs' encounters with patients [7].

In the last twenty years, great efforts have been made to improve the safety and quality of laboratory testing by reducing the number of errors made in selecting and ordering tests, and in reporting and interpreting the results of these tests [8]. However, more than $10 \%$ of errors still occur before a test specimen reaches the lab, and 5\% occur after the lab results are sent to the requesting physician [9]. A diagnosis error associated with the laboratory testing process (LTP) may be attributed to patient-related factors, to the physician's cognitive limitations, and/or to his or her interface with the lab ("handoff") [10].

In view of the preceding situation with regard to laboratory testing and the practice of laboratory medicine, the use by PCPs of health information exchange systems, and more precisely laboratory information exchange (LIE) systems, has become an essential aspect of the quest to improve the quality, safety, timeliness and cost effectiveness of patient care $[11,12]$. Enabled by information technology (IT) and usually designed to be interoperable, these systems are meant to support physicians' laboratory information gathering and clinical decision-making by providing them with the most relevant information at the most opportune time and location [13]. Importantly, the use of LIE systems is meant to diminish the possibility of diagnosis errors by overcoming physicians' cognitive limitations, which in turn improve the safety and quality of the LTP [14].

Among the various LIE systems that have been used by PCPs for laboratory medicine purposes electronic medical record (EMR) systems provide the essential information processing capacity in most primary care 
clinical settings [15]. These systems most often include functionalities for ordering laboratory tests and for accessing and managing the results of these tests [16]. They rarely include, however, a clinical decision support system module meant to help PCPs in ordering the most appropriate tests for their patients and interpreting these tests correctly $[17,18]$. Moreover, the different EMR artefacts offered by IT vendors now constitute the basic IT infrastructure of primary care medical practices [19]. Other LIE systems that may also be used by PCPs include state-, province- or countrywide interoperable electronic health record (iEHR) systems [20], as well as a laboratory results viewer (LRV) [21] which is a common interface that allows physicians to access test results from a medical laboratory's information system (LIS), a hospital's clinical information system (CIS) and/or a regional LIE platform [22].

In light of these considerations, we reviewed prior empirical studies on the use and impacts of EMR systems in primary care settings for purposes of supporting laboratory processes [e.g.,23-33]. For the most part, these studies examined a single EMR artefact or a single EMR functionality (e.g. reminding or alerting the PCP, or notifying the patient), were conducted within a single clinical setting or a limited number of settings and focused more on the sampled PCPs' satisfaction with EMR usage than on their effective use of such systems. Moreover, these studies provided mixed results as to the impacts of EMR use in the three phases of the LTP, that is, the pre-analytical, intraanalytical, and post-analytical phases. In the latter phase in particular, results are mixed or conflicting as to the true effectiveness of EMR system use in terms of the PCPs' monitoring and follow-up of their patients [33].

Given the need to deepen our understanding of the nature and effectiveness of PCPs' use of EMR systems for laboratory medicine purposes, this study seeks to answer the following research questions: What is the nature and extent of PCPs' use of EMR to support their practice of laboratory medicine? What LIE systems other than EMR systems do they use for such purposes? What are the contextual factors associated with an extended use of EMR systems for LTP in primary care settings? And most importantly, what are the impacts on PCPs' performance of their use of EMR systems for laboratory medicine?

\section{Methods}

As shown in Figure 1, a conceptual framework was developed to describe and explain PCPs' use of EMR systems for laboratory medicine purposes, as well as the potential antecedents and performance outcomes of such use. This framework guided the design of the survey study meant to answer our research questions. The framework is founded upon prior research on EMR system use in primary care $[19,34,35]$ and upon the previously mentioned literature review. Moreover, following Burton-Jones and Grange [36], we hold that using EMR systems per se may not necessarily improve the performance of PCPs. Our conceptual framework thus implies that only an "extended" use of EMR systems may have a positive impact on these clinicians' practice of laboratory medicine in terms of their efficiency and the quality of care provided to their patients [37].

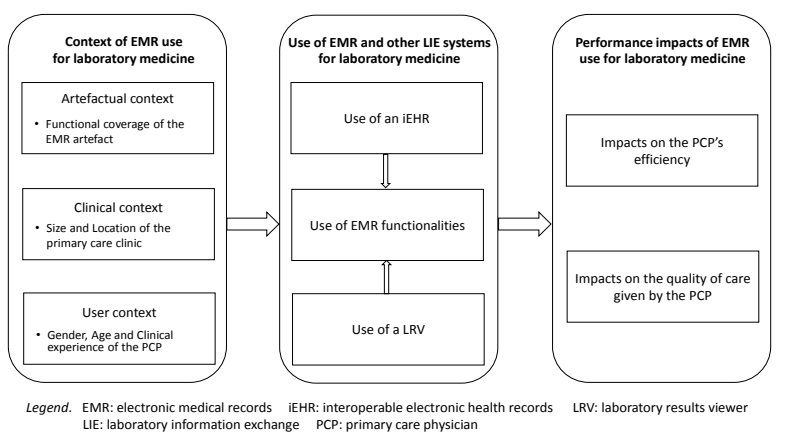

Figure 1. Conceptual Framework

As part of a broader research endeavour on the use of LIE systems in the province of Quebec, Canada, this study was designed as an online survey. As described below, this study followed best practices with regard to survey methodology [38]. The survey questionnaire was built following a review of the extant LIE literature and a series of interviews with 25 PCPs practicing in 11 different regions. Survey respondents were recruited with the help of the Quebec's Ministry of Health and Social Services, which emailed an invitation letter to the 9,005 physicians who are authorized to access the province-wide iEHR (i.e. the Quebec Health Record) system. The letter included a hyperlink and a QR code for mobile devices, directing respondents to access the survey questionnaire through a secure Web page. Developed with the Qualtrics online survey platform [39], the survey instrument was first approved by the province's health authorities and then pre-tested by 10 physicians. Each physician was interviewed as to the questionnaire's format and instructions, and as to the wording of questions and possible answers to ensure that these were interpreted as intended by the researchers. Following a few minor adjustments to the survey instrument, the study received final approval from the ethics committee of each researcher's institution. Two reminder letters were sent to all targeted physicians, that is, seven and fourteen days after the initial invitation. 
Our sample is composed of 684 general practitioners working in primary care settings, out of the 1,512 physicians who fully responded to the survey $(17 \%$ response rate). These PCPs are fairly representative, in terms of gender, age and clinical experience, of the targeted population. The potential for non-response bias was ascertained by comparing the 180 "late" respondents (i.e. those who answered after receiving the second reminder) with the 504 "early" respondents. No significant differences were found between these two groups, thus indicating the absence of such a bias. The data were then analyzed with descriptive and Chi-square statistics, as well as cluster analysis and ANOVA (using SPSS 24). As there were very few missing data, these were replaced by the mean value. The internal validity of the two index measures of EMR use was ascertained with "item analysis", that is, by confirming that each measure correlated sufficiently with the items that compose it [40, p. 169]. The internal validity of the two scale measures of the impacts of EMR use was tested with Cronbach's $\alpha$ coefficient (equal to 0.84 for efficiency and 0.83 for quality of care).

\section{Results}

Of the 684 respondents to the survey, 36\% were women (see Table 1). As for the respondents' age, $25 \%$ were less than 40 years old, and $19 \%$ were 60 years old or more. Less than half $(46 \%)$ had 25 years or more of clinical experience, whereas $22 \%$ had less than 10 years. A little more than half $(51 \%)$ practiced medicine in primary care clinics in which there were 10 physicians or less and which were located in rural (as opposed to urban) regions. They had 22 years' experience in the medical profession on average, with a minimum of 2 and a maximum of 45 .

Table 1. Characteristics of the PCPs as a function of their use of an EMR system for laboratory medicine purposes

\begin{tabular}{|c|c|c|c|c|}
\hline $\begin{array}{l}\text { Characteristics } \\
\text { of the PCPs }\end{array}$ & $\begin{array}{l}\text { All PCPs } \\
(\mathbf{N}=\mathbf{6 8 4}) \\
\text { freq. }(\%)\end{array}$ & $\begin{array}{c}\text { EMR users } \\
(\mathbf{n}=\mathbf{5 2 8}) \\
\text { freq. }(\%)\end{array}$ & $\begin{array}{c}\text { EMR non-users } \\
(\mathbf{n}=\mathbf{1 5 6}) \\
\text { freq. }(\%)\end{array}$ & $\begin{array}{c}\text { Chi-square } \\
\text { test }\end{array}$ \\
\hline $\begin{array}{l}\text { Gender } \\
\text { female } \\
\text { male }\end{array}$ & $\begin{array}{l}247(36) \\
433(64)\end{array}$ & $\begin{array}{ll}189 & (36) \\
335 & (64)\end{array}$ & $\begin{array}{ll}58 & (37) \\
98 & (63)\end{array}$ & 0.1 \\
\hline $\begin{array}{l}\text { Age } \\
29 \text { years old or less } \\
30-49 \text { years old } \\
50-59 \text { years old } \\
60 \text { years old or more }\end{array}$ & $\begin{aligned} & 40(6) \\
& 266(39) \\
& 245(36) \\
& 132(19) \\
&\end{aligned}$ & $\begin{aligned} & 31(6) \\
& 214(41) \\
& 187(35) \\
& 95(18) \\
&\end{aligned}$ & $\begin{aligned} & 9(6) \\
& 52(33) \\
& 58(37) \\
& 37(24) \\
&\end{aligned}$ & 4.1 \\
\hline $\begin{array}{l}\text { Clinical experience } \\
5 \text { years or less } \\
5-9 \text { years } \\
10-24 \text { years } \\
25 \text { years or more }\end{array}$ & $\begin{array}{rr}73 & (11) \\
76 & (11) \\
217 & (31) \\
317 & (46)\end{array}$ & $\begin{array}{r}54(10) \\
63(12) \\
175(33) \\
235(45)\end{array}$ & $\begin{array}{ll}19 & (12) \\
13 & (8) \\
42 & (27) \\
82 & (53)\end{array}$ & 5.3 \\
\hline $\begin{array}{l}\text { Size of the primary care clinic } \\
1 \quad \text { PCP } \\
2-5 \text { PCPs } \\
6-10 \text { PCPs } \\
11-20 \text { PCPs } \\
21 \text { PCPs or more } \\
\end{array}$ & $\begin{aligned} & 40(6) \\
& 125(18) \\
& 187(27) \\
& 243(36) \\
& 89(13) \\
&\end{aligned}$ & $\begin{aligned} & 23(4) \\
& 72(14) \\
& 142(27) \\
& 207(39) \\
& 84(16) \\
&\end{aligned}$ & $\begin{aligned} & 17(11) \\
& 53(34) \\
& 45(29) \\
& 36(23) \\
& 5(3) \\
&\end{aligned}$ & $60.0 * * *$ \\
\hline $\begin{array}{l}\text { Location of the primary care clinic } \\
\text { urban region } \\
\text { rural region }\end{array}$ & $\begin{array}{ll}332 & (48.5) \\
352 & (51.5)\end{array}$ & $\begin{array}{ll}243 & (46) \\
285 & (54)\end{array}$ & $\begin{array}{l}89(57) \\
67(43)\end{array}$ & $5.9 *$ \\
\hline
\end{tabular}

Nearly a fourth of the sampled PCPs (23\%) reported that their practice of laboratory medicine was not supported by an EMR system. These "non-users" differ from the 528 EMR users only to the extent that they tend to practice in smaller clinics and in more urban regions. With regard to the use of another LIE system for laboratory medicine in addition to - or in place of - an
EMR system, a little less than half of the respondents (47\%) indicated using a LRV for such purposes, whereas $82 \%$ use the province-wide iEHR system (as shown in Table 2). Interestingly, it was found that those respondents that do not use an EMR system tended to make greater use of a LRV ( $58 \%$ vs. $44 \%$ ) and of the iEHR system ( $88 \%$ vs. $80 \%)$. 
Table 2. Other LIE systems used for laboratory medicine by PCPs

\begin{tabular}{|c|c|c|c|c|}
\hline $\begin{array}{l}\text { Other LIE systems used } \\
\text { by the PCPs }\end{array}$ & $\begin{array}{l}\text { All PCPs } \\
(\mathbf{N}=\mathbf{6 8 4}) \\
\text { freq. }(\%) \\
\end{array}$ & $\begin{array}{c}\text { EMR users } \\
(\mathbf{n}=\mathbf{5 2 8}) \\
\text { freq. }(\%) \\
\end{array}$ & $\begin{array}{c}\text { EMR non-users } \\
(\mathbf{n}=\mathbf{1 5 6}) \\
\text { freq. }(\%)\end{array}$ & $\begin{array}{l}\text { Chi-square } \\
\text { test }\end{array}$ \\
\hline $\begin{array}{l}\mathbf{L R V}^{\text {a }} \\
\text { non-user } \\
\text { user }\end{array}$ & $\begin{array}{ll}359 & (52.5) \\
325 & (47.5) \\
\end{array}$ & $\begin{array}{ll}293 & (55.5) \\
235 & (44.5) \\
\end{array}$ & $\begin{array}{l}66(42) \\
90(58) \\
\end{array}$ & $8.4 * *$ \\
\hline $\begin{array}{l}\text { iEHR }^{\mathrm{b}} \\
\text { non-user } \\
\text { user } \\
\end{array}$ & $\begin{array}{l}122(18) \\
562(82)\end{array}$ & $\begin{array}{ll}103 & (19.5) \\
425 & (80.5)\end{array}$ & $\begin{array}{r}19(12) \\
137(88) \\
\end{array}$ & $4.4^{*}$ \\
\hline
\end{tabular}

As indicated in Table 3, our respondents perceived a number of clinical and communicational functionalities of an EMR system to be available to them, thus constituting their EMR system's artefactual capability for laboratory medicine. For instance, the capacity to "program blood test reminders in order to adjust medication dosages and/or prevent adverse effects" was available in $87 \%$ of the systems, whereas the capacity to "directly access from the EMR the lab test results provided by the QHR (iEHR)" was available in only $66 \%$. Moreover, we found that PCPs did not use all functionalities available in their EMR system. For instance, the two previously mentioned functionalities were actually used by $59 \%$ and $52 \%$ of the respondents, respectively. The extent to which a physician uses the EMR system was also ascertained, a functional use score being calculated as the ratio of the number of functionalities used over the total number of functionalities available. The PCPs thus use, on average, $84 \%$ of the laboratory functionalities available in their EMR system.

Table 3. Characterization of EMR system functionalities as used by PCPs for lab medicine

\begin{tabular}{|c|c|c|c|c|}
\hline EMR capability for laboratory medicine & $\begin{array}{l}\text { Availability } \\
\text { (\% of systems) }\end{array}$ & $\begin{array}{c}\text { Use } \\
(\% \text { of PCPs) }\end{array}$ & \multicolumn{2}{|c|}{$\begin{array}{l}\text { Extent of use } \mathbf{e}^{\mathrm{a}} \\
\text { mean s.d }\end{array}$} \\
\hline Communicational functionalities of the EMR system & & & \multirow[t]{4}{*}{0.82} & \multirow[t]{4}{*}{0.30} \\
\hline $\begin{array}{l}\text { The lab test results that I prescribe are directly delivered in the } \\
\text { EMR's inbox (or the equivalent). }\end{array}$ & $92.7 \%$ & $87.2 \%$ & & \\
\hline $\begin{array}{l}\text { In the EMR's inbox, a preliminary or partial result received can } \\
\text { inform me that a prescribed test is being processed by the lab. }\end{array}$ & $79.6 \%$ & $77.1 \%$ & & \\
\hline $\begin{array}{l}\text { When I click on a new lab test result, a note is automatically } \\
\text { documented in the EMR, thus acknowledging that I have revised } \\
\text { it. }\end{array}$ & $75.9 \%$ & $71.5 \%$ & & \\
\hline Clinical functionalities of the EMR system & & & \multirow[t]{5}{*}{0.84} & \multirow[t]{5}{*}{0.29} \\
\hline $\begin{array}{l}\text { When I revise lab test results in the EMR, I can insert clinical } \\
\text { annotations. }\end{array}$ & $94.4 \%$ & $88.3 \%$ & & \\
\hline $\begin{array}{l}\text { In the EMR, I can authorize my colleagues to access my inbox } \\
\text { in order to follow-up on my patients' test results when I am } \\
\text { absent from the clinic (on vacation, for instance). }\end{array}$ & $95.2 \%$ & $80.3 \%$ & & \\
\hline $\begin{array}{l}\text { With the EMR, I can program blood test reminders in order to } \\
\text { adjust medication dosages and/or prevent adverse effects. }\end{array}$ & $87.4 \%$ & $59.3 \%$ & & \\
\hline $\begin{array}{l}\text { From the EMR, I can directly access the lab test results provided } \\
\text { by the QHR [Quebec Health Record - iEHR]. }\end{array}$ & $66.5 \%$ & $52.3 \%$ & & \\
\hline \multicolumn{3}{|l|}{ Extent of EMR use for laboratory medicine } & 0.84 & 0.24 \\
\hline
\end{tabular}

Our next set of descriptive results pertains to the performance outcomes of EMR use in the practice of laboratory medicine, i.e. to the perceived impacts on the PCPs' efficiency and on the quality of the care given to their patients. As indicated in Table 4, these results confirm that "time is of the essence" for the physicians" activities within the LTP. Indeed, the two most important impacts of these physicians' use of EMR were 
their ability to gain time in the post-analytical phase of the LTP (efficiency), and to take faster action in this same phase as they follow-up on their patients' test results (quality of care). Moreover, these results provide relatively good news to EMR artefact designers and vendors in that the PCPs achieve, to a variable extent, most of the targeted performance outcomes of EMR use for laboratory medicine (with an average impacts score of 3.9, and a standard deviation of 0.8 , on 5-point Likert scales).

We then sought to determine the PCPs' EMR usage profile on the basis of their use of the communicational and clinical functionalities that constitute their EMR system. Through a cluster analysis, we grouped the physicians into clusters such that each cluster's membership is homogeneous with respect to their use of EMR systems. The SPSS Two-Step clustering algorithm was chosen as it can handle a large number of cases and automatically determine the optimal number of clusters [41]. A two-cluster solution was found to be optimal in identifying groups of PCPs that could be clearly distinguished from one another. Indeed, results in Table 5 reveal the existence of two EMR usage profiles.

Table 4. Performance impacts of PCPs' use of an EMR system for laboratory medicine

\begin{tabular}{|c|c|c|}
\hline Performance impacts of EMR use for laboratory medicine ${ }^{a}$ & mean & s.d. \\
\hline \multicolumn{3}{|l|}{ Efficiency of PCPs } \\
\hline I receive lab test results faster since I have been using the EMR. & 4.3 & 1.1 \\
\hline The information being in one place, I gain time when following-up on lab results through the EMR. & 4.2 & 1.0 \\
\hline I appreciate the flexibility provided by the EMR's mobility with regard to consulting lab results. & 4.1 & 1.1 \\
\hline Compared to paper, the EMR facilitates the insertion of clinical notes when revising lab results. & 3.9 & 1.2 \\
\hline With the EMR, I need not ask for my patients' paper file in order to consult their prior lab results. & 3.9 & 1.2 \\
\hline With the EMR, there is no need for me to use multiple information systems simultaneously. & 3.8 & 1.2 \\
\hline Lab test results originating in different regional facilities are directly transmitted to the EMR. & 3.8 & 1.4 \\
\hline The printing of lab reports has ceased in my practice since I have been using the EMR. & 3.4 & 1.5 \\
\hline Impacts on PCPs' efficiency ${ }^{b}$ & 3.9 & 0.8 \\
\hline \multicolumn{3}{|l|}{ Quality of care given by the physician } \\
\hline I can take faster action when receiving lab results. & 4.2 & 0.9 \\
\hline Due to the EMR's mobility, I can revise lab results anytime/anywhere, and thus intervene faster. & 4.2 & 1.1 \\
\hline Task assignments in the EMR improve our team's follow-up of lab results and team collaboration. & 4.0 & 1.0 \\
\hline The ability to share an inbox with a colleague in the EMR improves the follow-up of lab results. & 3.8 & 1.1 \\
\hline Managing lab results with the EMR lessens my risk of missing an important information. & 3.7 & 1.1 \\
\hline The ability to generate tables and graphs with the EMR is very helpful in interpreting lab results. & 3.7 & 1.1 \\
\hline Impacts on the quality of care given by $\mathbf{P C P s}^{\mathrm{c}}$ & 3.9 & 0.8 \\
\hline \multicolumn{3}{|l|}{$\begin{array}{l}\text { a as perceived by the PCP on Likert scales of } 1 \text { [strongly disagree] to } 5 \text { [strongly agree] } \\
{ }^{b} \text { mean of the eight efficiency impacts } \\
{ }^{c} \text { mean of the six quality of care impacts }\end{array}$} \\
\hline
\end{tabular}

Table 5. EMR usage profiles of the PCPs

\begin{tabular}{|l|c|c|c|}
\hline \multirow{2}{*}{ Extent of EMR use for laboratory medicine } & \multicolumn{2}{|c|}{ EMR usage profiles } & \\
\cline { 2 - 4 } & $\begin{array}{c}\text { Full users } \\
(\mathrm{n}=401) \\
\text { mean }\end{array}$ & $\begin{array}{c}\text { Partial users } \\
(\mathrm{n}=127) \\
\text { mean }\end{array}$ & $\begin{array}{c}\text { ANOVA } \\
\text { F }\end{array}$ \\
\hline Use of communicational functionalities & 0.96 & 0.40 & $873.3 * * *$ \\
Use of clinical functionalities & 0.94 & 0.52 & $327.1 * * *$ \\
\hline a no. of functionalities used / no. of functionalities available & $* * * \mathrm{p}<0.001$ & & \\
\hline
\end{tabular}

Drawing upon the previously mentioned notion of "extended" use of EMR systems, the 401 physicians (76\% of the EMR users) who constitute the first EMR usage profile were called Full users, as they were found to make use of all EMR functionalities available for laboratory medicine (on average, $96 \%$ and $94 \%$ of their system's communicational and clinical functionalities, respectively). In contrast to the first profile, the 127 physicians (24\%) constituting the second group were named Partial users as their use of EMR systems is much narrower on all communicational and clinical functionalities (on average, $40 \%$ and $52 \%$, 
respectively), noting that their most significant difference with the first profile was in their lower use of the "lab test results directly delivered in the EMR's inbox" communicational functionality (54\% vs. 97\%) and of the "authorize my colleagues to access my inbox to follow-up on my patients' test results when I am absent" clinical functionality (48\% vs. 94\%).

In order to identify the clinical-, artefactual-, and user-related antecedents of the PCPs' use of EMR systems for laboratory medicine purposes, we sought to contextualize the two usage profiles that emerged from the cluster analysis, as shown in Table 6. In this regard, one first notes that Full users differ markedly from Partial users in terms of their EMR system's functional coverage, as the number of communicational and clinical functionalities available to the first user group is significantly greater. This again points to the fact that "not all EMR artefacts are created equal" by their designers [19]. Moreover, a significantly greater proportion of Partial users use a LRV as a LIE system in addition to - and concomitantly with - their EMR system, that is, $48 \%$ vs $43 \%$ for the Full users.

Table 6. Characterization of the EMR usage profiles of the PCPs

\begin{tabular}{|c|c|c|c|}
\hline \multirow[b]{2}{*}{$\begin{array}{l}\text { Characterization of the PCPs' use } \\
\text { of an EMR system for laboratory medicine }\end{array}$} & \multicolumn{2}{|c|}{ EMR usage profiles } & \multirow[b]{2}{*}{$\begin{array}{c}\text { ANOVA } \\
\text { F }\end{array}$} \\
\hline & $\begin{array}{c}\text { Full users } \\
(\mathrm{n}=401) \\
\text { mean }\end{array}$ & $\begin{array}{l}\text { Partial users } \\
(\mathrm{n}=127) \\
\text { mean }\end{array}$ & \\
\hline $\begin{array}{l}\text { Other LIE systems used for laboratory medicine } \\
\text { LRV user [0: no, } 1: \text { yes }] \\
\text { iEHR user } \quad[0: \text { no, } 1: \text { yes }]\end{array}$ & $\begin{array}{l}0.43 \\
0.82 \\
\end{array}$ & $\begin{array}{l}0.48 \\
0.75 \\
\end{array}$ & $\begin{array}{l}3.1^{*} \\
1.1\end{array}$ \\
\hline $\begin{array}{l}\text { Artefactual context (functional coverage of the EMR artefact) } \\
\text { No. of communicational functionalities available } \\
\text { No. of clinical functionalities available }\end{array}$ & $\begin{array}{l}2.5 \\
3.1 \\
\end{array}$ & $\begin{array}{l}1.8 \\
2.2 \\
\end{array}$ & $\begin{array}{l}26.7 * * * \\
54.7 * * * \\
\end{array}$ \\
\hline $\begin{array}{l}\text { Clinical context } \\
\text { Size of the primary care clinic }{ }^{\mathrm{a}} \\
\text { Location of the clinic [0: urban region, 1: rural region] }\end{array}$ & $\begin{array}{c}3.6 \\
0.56 \\
\end{array}$ & $\begin{array}{c}3.3 \\
0.49 \\
\end{array}$ & $\begin{array}{l}7.4 * * \\
9.7 * * *\end{array}$ \\
\hline $\begin{array}{l}\text { User context } \\
\text { Gender } \quad[0: \text { male, } 1: \text { female }] \\
\text { Age }^{\mathrm{b}} \\
\text { Clinical experience }^{\mathrm{c}}\end{array}$ & $\begin{array}{c}0.61 \\
3.4 \\
4.4\end{array}$ & $\begin{array}{l}0.72 \\
3.4 \\
4.4\end{array}$ & $\begin{array}{l}5.0 * \\
0.3 \\
0.0\end{array}$ \\
\hline
\end{tabular}

Regarding the clinical context of EMR use, it was found that Full users differed significantly from Partial users in that the physicians in the first group tend to practice laboratory medicine in primary care clinics of greater size on average, and more in rural (vs. urban) regions. This result may be related to previous findings on the greater use of EMR systems in rural areas [42]. As to the user context, male physicians are found in the
Full users group in significantly greater proportion than their female counterparts. This last result may be related to previous findings on the effects of gender upon an individual's intention to explore IT and his or her IT usage scope [43]. However, there are no significant differences between the two EMR usage profiles in terms age and clinical experience.

Table 7. EMR impacts profiles of the PCPs (cluster analysis)

\begin{tabular}{|c|c|c|c|c|}
\hline \multirow[b]{2}{*}{$\begin{array}{l}\text { Performance impacts of PCPs' use of EMR } \\
\text { for laboratory medicine }{ }^{\mathrm{a}}\end{array}$} & \multicolumn{3}{|c|}{ EMR impacts profiles } & \multirow[b]{2}{*}{$\begin{array}{c}\text { ANOVA } \\
\text { F }\end{array}$} \\
\hline & $\begin{array}{c}\text { Strongly-Impacted } \\
\text { users } \\
(\mathrm{n}=230) \\
\text { mean }\end{array}$ & $\begin{array}{c}\text { Weakly-Impacted } \\
\text { users } \\
(\mathrm{n}=235) \\
\text { mean }\end{array}$ & $\begin{array}{c}\text { Unimpacted } \\
\text { users } \\
(\mathrm{n}=63) \\
\text { mean }\end{array}$ & \\
\hline Impacts on PCPs' efficiency & $4.6_{1}$ & $3.7_{2}$ & $2.3_{3}$ & $810.4 * * *$ \\
\hline Impacts on the quality of care given by PCPs & 4.61 & $3.7_{2}$ & 2.43 & $738.0 * * *$ \\
\hline
\end{tabular}

With regard to our last research question and in line with our conceptual framework, we then sought to determine the respondents' profile on the basis of the performance impacts resulting from their use of an EMR system for laboratory medicine. Through a cluster analysis similar to the previous one, the PCPs were 
grouped under three profiles that could be clearly distinguished from one another and were respectively named Strongly-Impacted $(\mathrm{n}=230)$, Weakly-Impacted $(\mathrm{n}=235)$ and Unimpacted users $(\mathrm{n}=63)$. As shown in Table 7, the first group of users $(43.5 \%)$ is constituted of physicians who view EMR usage as having a strong influence on their practice of laboratory medicine, that is, on their efficiency and on the quality of the care they provide to their patients (with a mean impacts score of 4.6, on 5-point Likert scales). Those in the second group $(44.5 \%)$ perceive this influence to be significantly weaker (with a mean impacts score of 3.7) whereas the PCPs in the third group (12\%) perceive their use of an EMR system to have no influence whatsoever on their performance (with a mean score of 2.4).

Table 8. Characterization of the EMR impacts profiles of the PCPs

\begin{tabular}{|c|c|c|c|c|}
\hline \multirow[b]{2}{*}{$\begin{array}{l}\text { Characterization of the impacts of PCPs' use } \\
\text { of an EMR system for laboratory medicine }\end{array}$} & \multicolumn{3}{|c|}{ EMR impacts profiles } & \multirow[b]{2}{*}{$\begin{array}{c}\text { ANOVA } \\
\mathbf{F}\end{array}$} \\
\hline & $\begin{array}{c}\text { Strongly-Impacted } \\
\text { users } \\
(\mathrm{n}=230) \\
\text { mean }\end{array}$ & $\begin{array}{l}\text { Weakly-Impacted } \\
\text { users } \\
(\mathrm{n}=235) \\
\text { mean }\end{array}$ & $\begin{array}{l}\text { Unimpacted } \\
\text { users } \\
(\mathrm{n}=63) \\
\text { mean }\end{array}$ & \\
\hline $\begin{array}{l}\text { Extent of EMR use for laboratory medicine } \\
\text { Use of communicational functionalities } \\
\text { Use of clinical functionalities }\end{array}$ & $\begin{array}{l}0.91_{1} \\
0.90_{1}\end{array}$ & $\begin{array}{l}0.81_{2} \\
0.84_{2}\end{array}$ & $\begin{array}{l}0.61_{3} \\
0.61_{3}\end{array}$ & $\begin{array}{l}27.6^{* * * *} \\
29.1 * * *\end{array}$ \\
\hline $\begin{array}{l}\text { Other LIE systems used for laboratory med. } \\
\text { LRV user [0: no, } 1: \text { yes }] \\
\text { iEHR user }[0: \text { no, } 1: \text { yes }] \\
\end{array}$ & $\begin{array}{l}0.41_{2} \\
0.82 \\
\end{array}$ & $\begin{array}{l}0.44 \\
0.78\end{array}$ & $\begin{array}{c}0.59_{1} \\
0.85\end{array}$ & $\begin{array}{l}3.1^{*} \\
1.1\end{array}$ \\
\hline $\begin{array}{l}\text { Artefactual context (functional coverage) } \\
\text { No. of communicational functionalities avail. } \\
\text { No. of clinical functionalities available }\end{array}$ & $\begin{array}{l}2.61 \\
3.3_{1} \\
\end{array}$ & $\begin{array}{l}2.2_{2} \\
2.8_{2} \\
\end{array}$ & $\begin{array}{l}1.8_{3} \\
2.0_{3} \\
\end{array}$ & $\begin{array}{l}26.7 * * * \\
54.7 * * * \\
\end{array}$ \\
\hline $\begin{array}{l}\text { Clinical context } \\
\text { Size of the primary care clinic } \\
\text { Location } \quad \text { [0: urban region, 1: rural region] }\end{array}$ & $\begin{array}{c}3.7 \\
0.63_{1} \\
\end{array}$ & $\begin{array}{c}3.4 \\
0.51_{2} \\
\end{array}$ & $\begin{array}{c}3.4 \\
0.32_{3} \\
\end{array}$ & $\begin{array}{l}1.9 \\
9.7 * * * \\
\end{array}$ \\
\hline $\begin{array}{l}\text { User context } \\
\text { Gender }[0: \text { male, } 1 \text { : female }] \\
\text { Age }^{\mathrm{c}} \\
\text { Clinical experience }^{\mathrm{d}}\end{array}$ & $\begin{array}{l}0.59 \\
3.5 \\
4.5\end{array}$ & $\begin{array}{r}0.67 \\
3.4 \\
4.2 \\
\end{array}$ & $\begin{array}{l}0.72 \\
3.4 \\
4.5 \\
\end{array}$ & $\begin{array}{l}2.4 \\
0.4 \\
1.4 \\
\end{array}$ \\
\hline $\begin{array}{l}\text { a no. of functionalities used } / \text { no. of functionalitie } \\
\text { b } 1=1 \text { PCP, } 2=2-5,3=6-10,4=11-20,5=21 \\
\text { c } 1=30 \text { years old or less, } 2=30-39,3=40-49, \\
\text { d } 1=5 \text { years or less, } 2=5-9,3=10-14,4=15 \\
\text { Vota. Within rows, different subscripts indicate si }\end{array}$ & $\begin{array}{l}\text { ailable } \\
\text { s or more } \\
50-59,5=60 \text { yea } \\
5=20-24,6=25 \\
\text { icant }(p<0.05) \text { pai }\end{array}$ & $\begin{array}{l}* \mathrm{p}<0.05 \quad * * \\
\text { ld or more } \\
\text { is or more }\end{array}$ & 0.001 & 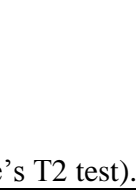 \\
\hline
\end{tabular}

Last, in line with our conceptual framework, we ascertained the degree to which PCPs in the three groups differed in terms of their use of an EMR system. As shown in Table 8, analyses of variance show unequivocally that the physicians profiled as being Strongly-Impacted are those that make the most extensive use of their EMR system, and whose system possesses the strongest EMR capability for laboratory medicine. Conversely, physicians profiled as being Unimpacted are those that make the least use of their system, and whose EMR capability is the weakest in terms of the communicational and clinical functionalities available to them. More precisely, PCPs in the latter group uses, on average, $61 \%$ of the clinical functionalities available in their system, as opposed to 90\% for the former group. For their part, physicians profiled as being Weakly-Impacted stand squarely in the middle-between the other two profiles, as they differ significantly with both the Strongly-Impacted and Unimpacted users in the extensiveness of their EMR usage, and in the strength of the EMR capability at their disposal. Finally, given preceding results of the characterization of the two EMR usage profiles, it is not surprising to find that the Unimpacted physicians use a LRV and practice in urban regions in greater proportion than those in the other two profiles.

\section{Discussion}

The findings of the present study confirm that the use of EMR systems in support of laboratory medicine is associated with improved performance in primary care settings. However, we also observed substantial variability in terms of PCPs' actual use of such systems, and in terms of the performance impacts that ensue from this use. This variability can be attributed to differences in the EMR artefactual capability that is available to physicians, and in turn to differences in the nature and 
extent of EMR usage by PCPs, thus providing the basic answers to this study's research questions.

To achieve our research objectives, we first looked at the extent to which PCPs actually use the EMR systems made available to them. Our findings show that physicians used, on average, $84 \%$ of all the functionalities available in the EMR systems deployed in their medical practices to support the LTP. This EMR usage was combined in most cases with the use of one or two additional LIE systems, that is, the province-wide iEHR system and/or a LRV. More precisely, only $10 \%$ of physicians solely used their EMR system whereas $45 \%$ used it in tandem with the iEHR system, $10 \%$ in tandem with a LRV, and $35 \%$ used all three types of systems. This demonstrates the polymorphous nature of IT usage in primary care settings, as it would appear that no single type of system meets all of the PCPs' needs within the LTP.

Additional analyses of these physicians' EMR usage behaviors allowed us to separate them into two distinct groups, namely, Partial and Full users. Physicians in the former group used on average $47 \%$ of the functionalities potentially available in an EMR system compared to $95 \%$ for the latter group. Ultimately, we found that those physicians who were Strongly-Impacted were the ones whose EMR usage could be qualified as Full, that is, who got the most out of their EMR system's capability by using significantly more of its communicational and clinical functionalities to support their practice of laboratory medicine.

Yet, our findings clearly indicate that StronglyImpacted physicians remain a minority (44\%) of EMR users, and that there remains a significant number of users $(12 \%)$ whose practice of laboratory medicine is unimpacted. There is thus a need, emanating from this study, to further investigate the artefactual, clinical and legal factors that motivate or persuade physicians to further appropriate their EMR system and subsequently use a broader range of functionalities in support of their communicational and clinical activities within the LTP. For one thing, our findings reveal that a more extensive usage of EMR systems in primary care settings requires software products to be more "aligned" with the LTP and to have a wider scope (functional coverage/ integration) with regard to all phases of the process and all of the PCPs' diagnosis activities within this process (information gathering, information integration and interpretation, working diagnosis, communication of diagnosis, and treatment) [44].

Our findings also confirm that functional design differences between EMR systems influence their usage in primary care settings, and especially within the LTP, given its increasingly critical role in contemporary healthcare. This challenges software developers and vendors concerning not only the interoperability of their
EMR products with other systems, but also concerning how to approach the functional design of these products to generate broader support for the physicians' decisions and actions throughout the LTP.

In view of these findings, future research could capitalize on the notion of "extended use" to acquire a better understanding of other artefactual, clinical and user-related determinants of EMR usage within the LTP $[19,37]$. For instance, the EMR artefact's "usability", as perceived by the PCPs in terms of managing their patients' test results and coordinating with the other actors involved in the LTP, should come into play [45]. Future studies could also theorize the "effective use" of an EMR artefact within the specific context of the LTP [46], as this would enhance our understanding of the manner by which the use of this IT artefact impacts the practice of laboratory medicine in primary care settings [47].

\section{Conclusion}

In this study, we sought to develop a better understanding of how PCPs are using the IT tools at their disposal to consult and manage their patients' laboratory test results, as well as the performance improvements they derive from such use. In so doing, we have answered calls to study LIE usage in greater breadth and depth [12,48], firstly by examining individual physicians' use of EMR system functionalities and the primary care context of this use, and secondly by ascertaining these EMR users' application of the information provided by the system to improve their practice of laboratory medicine.

Our findings must be considered in light of the study's response rate and the usual limitations associated with survey research, as there may still be biases related to the perceptual nature of the performance outcome data. Furthermore, the variability observed in the performance outcomes could be explained through a better understanding of the clinical and laboratory environments of this use. In this regard, integrating LIE usage into a prescriptive LTP model [e.g. 10,33,49], would deepen our understanding of how this use affects the LTP, and how improved performance ensues in terms of physician efficiency, quality of care, and patient safety. In this line of thought, case studies of EMR usage for laboratory medicine in a variety of primary care settings should help us improve our understanding of this process and, hence, contribute to the performance of primary care physicians and clinics.

The majority of our respondents indicated that their practice of laboratory medicine was positively impacted by their use of an EMR system. Even more encouraging is the fact that the more extensive this use, the higher the 
perceived impacts. More specifically, extended use of the EMR system allows PCPs to intervene promptly with their patients and make informed clinical decisions, due in part to the laboratory results (and, in particular, abnormal and critical results) that are made available in a timely manner. In other words, extended use of an EMR system allows PCPs to better ascertain and monitor the health status of their patients, verify their diagnosis assumptions and, if their system includes a clinical decision support module, apply evidence-based practices in laboratory medicine (e.g. in test selection and interpretation). But in order for such impacts to be realized, one must ensure that physicians are provided with high-quality EMR systems producing accurate, precise, up-to-date, relevant, complete and easy-tointerpret information in a timely manner.

\section{References}

[1] Broemeling, A.M., Watson, D.E., \& Prebtani, F. (2008). Population patterns of chronic health conditions, co-morbidity and healthcare use in Canada: implications for policy and practice. Healthcare Quarterly, 11(3), 70-76.

[2] Hickner, J. M., Fernald, D. H., Harris, D. M., Poon, E. G., Elder, N. C., \& Mold, J. W. (2005). Issues and initiatives in the testing process in primary care physician offices. Joint Commission Journal on Quality and Patient Safety, 31(2), 8189.

[3] Marques, M.B., Hickner, J., Thompson, P.J., \& Taylor, J. (2014). Primary care physicians and the laboratory: Now and the future. American Journal of Clinical Pathology, 142, 738740 .

[4] Elder, N., Hickner, J., \& Graham, D. (2008). Quality and safety in outpatient laboratory testing. Clinics in Laboratory Medicine, 28(2), 295-303.

[5] Litchfield, I.J., Bentham, L.M., Lilford, R.J., \& Greenfield, S.M. (2014). Test result communication in primary care: clinical and office staff perspectives. Family Practice, 31(5), 592-597.

[6] Hickner, J., M., Graham, D. G., Elder, N. C., Brandt, E., Emsermann, C. B., Dovey, S., \& Phillips, R. (2008). Testing process errors and their harms and consequences reported from family medicine practices: a study of the American Academy of Family Physicians National Research Network. Quality and Safety in Health Care, 17(3), 194-200.

[7] Plebani, M. (2009). Exploring the iceberg of errors in laboratory medicine. Clinica Chimica Acta, 404(1), 16-23.

[8] Plebani, M., Laposata, M., \& Lundberg, G.D. (2011). The brain-to-brain loop concept for laboratory testing 40 years after its introduction. American Journal of Clinical Pathology, 136(6), 829-833.

[9] Norman, GR, \& Eva, K.W. (2010). Diagnostic error and clinical reasoning. Medical Education, 44(1), 94-100.

[10] West, D.R., James, K.A., Fernald, D.H., Zelie, C., Smith, M.L., \& Raab, S.S. (2014). Laboratory medicine handoff gaps experienced by primary care practices: A report from the shared networks of collaborative ambulatory practices and partneers (SNOCAP). Journal of the American Board of Family Medicine, 27(6), 796-803.

[11] Ross, S.E., Schilling, L.M., Fernald, D.H., Davidson, A.J., \& West, D.R. (2010). Health information exchange in small-to-medium sized family medicine practices: Motivators, barriers, and potential facilitators of adoption. International Journal of Medical Informatics, 79(2), 123-129.

[12] Dullabh, P., \& Moiduddin, A. (2009). Electronic Exchange of Clinical Laboratory Information: Issues and Opportunities, Office of the Assistant Secretary for Planning and Education (ASPE), Department of Health \& Human Services, USA.

[13] Beasley, J.W., Wetterneck, T.B., Temte, J., Lapin, J.A., Smith, P., Rivera-Rodriguez, A.J., et al. (2011). Information chaos in primary care: Implications for physician performance and patient safety. Journal of the American Board of Family Medicine, 24(6), 745-751.

[14] Singh, H., Thomas, E.J., Sittig, D.F., Wilson, L., Espadas, D., et al. (2010). Notification of abnormal lab test results in an electronic medical record: Do any safety concerns remain? American Journal of Medicine, 123(3), 238-244.

[15] Tu, K., Mitiku, T. F., Ivers, N. M., Guo, H., Hong, L., et al. (2014). Evaluation of electronic medical record administrative data linked database (EMRALD). American Journal of Managed Care, 20(1), e15-e21.

[16] Hickner, J., M., Thompson, P. J., Wilkinson, T., et al. (2014). Primary care physicians' challenges in ordering clinical laboratory tests and interpreting results. Journal of the American Board of Family Medicine, 27(2), 268-274.

[17] Delvaux, N., De Sutter, A., Van de Velde, S., Ramaekers, D., Fieuws, S., \& Aertgeerts, B. (2017). Electronic Laboratory Medicine ordering with evidence-based Order sets in primary care (ELMO study): protocol for a cluster randomised trial. Implementation Science, 12(147), 1-8.

[18] Fischer, S., Tjia J., Reed, G., Peterson, D., Gurwitz, J., \& Field, T. (2014). Factors associated with ordering laboratory monitoring of high-risk medications. Journal of General Internal Medicine, 29(12), 1589-1598.

[19] Raymond, L., Paré, G., \& Marchand, M. (2017). Extended use of electronic health records by primary care physicians: Does the EHR artefact matter? Health Informatics Journal, https://doi.org/10.1177/1460458217704256, 1-12.

[20] Giokas, D. (2004). Canada Health Infoway - Towards a national interoperable electronic health record (EHR) solution. Studies in Health Technology and Informatics, 115, 108-140

[21] Kreuter, J.M., \& Basch, P. (2007). A clinician-centric medical results viewer. Health Management Technology, 28(2), 56-60.

[22] Hyppönen, H., Reponen, J., Lääveri, T., \& Kaipio, J. (2014). User experiences with different regional health information exchange systems in Finland. International Journal of Medical Informatics, 83(1), 1-18.

[23] Murff, H. J., Gandhi, T. K., Karson, A. K., Mort, E. A., Poon, E. G., Wang, S. J., et al. (2003). Primary care physician attitudes concerning follow-up of abnormal test results and 
ambulatory decision support systems. International Journal of Medical Informatics, 71(2-3), 137-149.

[24] Feldstein, A.C., Smith, D.H., Perrin, N., et al. (2006). Improved therapeutic monitoring with several interventions: A randomized trial. Archives of Internal Medicine. 166(17), 1848-1854.

[25] Casalino, L.P., Dunham, D., Chin, M.H., Bielang, R., Kistner, E.O., et al. (2009). Frequency of failure to inform patients of clinically significant outpatient test results. Archives of Internal Medicine, 169(12), 1123-1129.

[26] Ferris, T.G., Johnson, S.A., Co, J.P., Backus, M., Perrin, J., Bates, D.W., et al. (2009). Electronic results management in pediatric ambulatory care: qualitative assessment. Pediatrics, 123(Suppl 2), S85-S91.

[27] Smith, D. H., Feldstein, A. C., Perrin, N. A., Yang, X., Rix, M. M., et al. (2009). Improving laboratory monitoring of medications: an economic analysis alongside a clinical trial. American Journal of Managed Care, 15(5), 281-289.

[28] Elder, N., McEwen, T., Flach, J., Gallimore, J., \& Pallerla, H. (2010). The management of test results in primary care: does an electronic medical record make a difference? Family Medicine, 42(5), 327-333.

[29] Blaya, J.A., Shin, S., Contreras, C., Yale, G., Suarez, C., Asencios, L., et al. (2011). Full impact of laboratory information system requires direct use by clinical staff: cluster randomized controlled trial. Journal of the American Medical Informatics Association, 18(1), 11-16.

[30] Urban, E., Ose, D., Joos, S., Szecsenyi, J., \& Miksch, A. (2012). Technical support and delegation to practice staff status quo and (possible) future perspectives for primary health care in Germany. BMC Medical Informatics and Decision Making, 12(1), 1-7.

[31] Al Alawi, S., Al Dhaheri, A., Al Baloushi, D., Al Dhaheri, M., \& Prinsloo, E.A.M. (2014). Physician user satisfaction with an electronic medical records system in primary healthcare centres in Al Ain: a qualitative study. BMJ Open, 4(11), 1-8.

[32] Blaya, J.A., Shin, S.S., Yagui, M., Contreras, C., Cegielski, P., Yale, G., et al. (2014). Reducing communication delays and improving quality of care with a tuberculosis laboratory information system in resource poor environments: a cluster randomized controlled trial. PloS one, 9(4), 1-7.

[33] Maillet, É., Paré, G., Currie, L.M., Raymond, R., Ortiz de Guinea, A., Trudel, M-C \& Marsan, J. (2018). Laboratory testing in primary care: a systematic review of health IT impacts. International Journal of Medical Informatics, in press, https://doi.org/10.1016/j.ijmedinf.2018.05.009.

[34] Sykes, T.A., Venkatesh, V., \& Rai, A. (2011). Explaining physicians' use of EHR systems and performance in the shakedown phase. Journal of the American Medical Informatics Association, 18(2), 125-130.

[35] Paré, G., Raymond, L., Ortiz de Guinea, A., Poba-Nzaou, P., Trudel, M.-C., Marsan, J., \& Micheneau, T. (2015). Electronic health record usage behaviors in primary care medical practices: A survey of family physicians in Canada. International Journal of Medical Informatics, 84(10), 857867.
[36] Burton-Jones, A., \& Grange, C. (2013). From use to effective use: a representation theory perspective. Information Systems Research, 24(3), 632-658.

[37] Hsieh, J.J.P.A., \& Wang, W. (2007). Explaining employees' extended use of complex information systems. European Journal of Information Systems, 16(3), 216-227.

[38] Kelley, K., Clark, B., Brown, V., \& Sitzia, J. (2003). Good practice in the conduct and reporting of survey research. International Journal for Quality in Health Care, 15(3), 261266.

[39] Snow, J. (2012). Qualtrics Survey Software - Handbook for Research Professionals. Provo, Utah: Qualtrics Labs, Inc.

[40] Babbie, E. (2013). The Practice of Social Research. Thirteenth Edition, Belmont, California: Wadsworth.

[41] Gelbard, R., Goldman, O., \& Spiegler, I. Investigating diversity of clustering methods: an empirical comparison. Data \& Knowledge Engineering, 63(1), 155-166.

[42] Whitacre, B.E. (2015). Rural EMR adoption rates overtake those in urban areas. Journal of the American Medical Informatics Association, 22(2), 399-408.

[43] Maruping, L.M., \& Magni, M. (2012). What's the weather like? The effect of team learning climate, empowerment climate, and gender on individuals' technology exploration and use. Journal of Management Information Systems, 29(1), 79-114.

[44] Balogh, E.P., Miller, B.T., \& Ball, J.R. (2015). Improving Diagnosis in Health Care. National Academy of Medicine, Washington, DC: National Academies Press.

[45] Myers, J.J., Koester, K.A., Chakravarty, D., Pearson, C., Maiorana, A., Shade, S.B., \& Steward, W.T. (2012). Perceptions regarding the ease of use and usefulness of health information exchange systems among medical providers, case managers and non-clinical staff members working in HIV care and community settings. International Journal of Medical Informatics, 81(10), e21-e29.

[46] Burton-Jones, A., \& Volkoff, O. (2017). How can we contextualize theories of effective use? A demonstration in the context of community-care electronic health records. Information Systems Research, 28(3), 468-489.

[47] Marchand, M., \& Raymond, L. (2017). Characterizing, explaining and valuing the effective use of an IT artefact: A field study of performance management information systems in SMEs. Proceedings of the 50th Hawaii International Conference on System Sciences, Kailua-Kona, Hawaii, 50275036.

[48] Vest, J.R., \& Jasperson, J. (2011). What should we measure? Conceptualizing usage in health information exchange. Journal of the American Medical Informatics Association, 17(2), 302-307.

[49] Fernald, D., Hamer, M., James, K., Tutt, B., \& West, D. (2015). Launching a laboratory testing process quality improvement toolkit: From the shared networks of Colorado ambulatory practices and partners (SNOCAP). Journal of the American Board of Family Medicine, 28(5), 576-583. 